\title{
A Monster We Love: Dexter's Reproductive Futures
}

\author{
Randal Rogers \\ University of Regina, Regina, SK, Canada
}

\begin{abstract}
While there has been significant scholarly attention to the Showtime Series Dexter (2006-13) and the fundamental choice between being good or evil that its protagonist Dexter Morgan must make, this article advances scholarship in three ways. Firstly, it examines Dexter's final twist in plot and the decision Dexter makes to finally embrace his "dark passenger" to argue for the necessity of the plot twist to the series, which scholarship has not yet performed. Secondly, by situating Dexter's decision within a framework focused on reproductive futurism, a revised and more nuanced approach to Dexter's ontological dilemma can be proffered. Finally, by locating Dexter's dark passenger within the theoretical frames of reproductive futurism and community this article adds an important dimension to notions of the monster conventionally rooted in theories of identity and subjectivity. In the final moments of the series everything changes for Dexter as his identity is redeemed for a reproductive future without guarantees, which this article argues is germane to considerations of biopolitics and community in the contemporary period.
\end{abstract}

Keywords: Dexter, reproductive future, biopolitics, community, serial killers, monsters, redemption

\section{Introduction}

After eight seasons the Showtime television series Dexter (2006-13) ended with equal measures of fanfare and disappointment for its fans. ${ }^{1}$ The critically acclaimed series, which tracked the double life of its protagonist Dexter Morgan, a blood spatter specialist who worked for the Miami Police Department and was a serial killer, made a significant mark on the television landscape. ${ }^{2}$ Expanding the paranoid genre by using a quirky, awkward and at times creepy forensic specialist as its protagonist, and balancing the gravity of the police procedural with the series' particular brand of dark humor, Dexter offered many exciting narrative and aesthetic twists and turns to audiences. At the centre of these existed an impasse in Dexter's own identity that was traced from season to season as he negotiated the relationship between a necessary desire for communal belonging and an equally fundamental drive to kill (Arellano, 2012, pp. 132-133). Once Dexter's propensities were uncovered, as a protective mechanism Dexter's adoptive father Harry provided a unique moral framework, the "Code of Harry," within which to kill, a means by which to serve Dexter’s “dark passenger”- the description he used to define his

Randal Rogers, Doctor of Philosophy, Associate Professor, Faculty of Media, Art, and Performance, University of Regina.

${ }^{1}$ An immediate qualification is needed. The current study in not a study of audience but does refer to fans and their reactions in two places. When referring to fans I do so as one who has read numerous discussion boards on Dexter and has actively engaged as a fan of the series. My references to fandom are therefore less formal than a study of audience requires. In referring to fans I do not make definitive claims; rather, I refer to a general sensibility both expressed on fan sites for the series and by me.

${ }^{2}$ For critical overviews of Dexter see: Bella DePaulo (Ed.), The Psychology of Dexter (2010); Richard Greene, George A. Reisch and Rachel Robison-Greene (Eds.), Dexter and Philosophy (2011); Douglas K. Howard (Ed.), Dexter: Investigating Cutting Edge Television (2010). 
inner serial killer-while remaining hidden from detection (Green, 2011, p. 23). Yet, Dexter was repeatedly haunted in the series by a need to break from convention and be true to himself by embracing his dark passenger and living outside the law. As Dexter moved from season to season this core dilemma was tracked while its central protagonist investigated and killed his own self-determined set of murderers, learned his own history, negotiated familial relations, and evolved into a human with authentic feelings.

Returning to key questions about Dexter and the impasse that marked his identity this article introduces a framework that has not yet been fully traced for the series. Drawing on Lee Edelman's critique of reproductive futurism in which the future potential of the figural child is the unique ground of the political, one he ardently propounds in No Future: Queer Theory and the Death Drive, the present article argues that Dexter's final choice in the series was important to both the closure that Dexter's identity search demanded and to that of the series itself. Reproduction of the social order, particularly in the name of the child and the future it allegedly holds in trust, was a central preoccupation for the series. However, when filtered through Dexter's ongoing crisis of identity, the crucial question turned on which form reproduction would take as Dexter asked whether he was good or evil by nature. This article begins with the assertion that Judith Butler makes in Giving an Account of Oneself regarding the primary opacity of the subject regarding questions of self-knowledge, produced as the subject always must be in media res. This is followed by a discussion of serial killers and community, drawing upon Roberto Esposito's work on immunitas to argue that serial killers be considered a "necessary negative" existing inside community rather than its constitutive exterior. Lastly, Dexter's final decision to embrace his monstrous future is examined through the lens of redemption. But to begin, a description of Dexter's ultimate turning point in the finale of the series is needed.

\section{Endings}

The series finale of Dexter, aptly titled Remember the Monsters?, left many fans noting how it was a desperate effort to rescue a season — and perhaps the series—from having slipped into irrelevance (Dietz, 2013). The narrative of the final episode begins as a hurricane approaches Miami and Dexter arrives at the hospital where his sister Deb, a detective, is on life support after having been shot by Oliver Saxon, Dexter's primary target for season eight. Dexter speaks to her, apologizes, and tells Deb that he loves her while unhooking the respirator keeping her alive. He then takes her body to his boat and tacks toward the approaching storm. Arriving at his much-used ocean burial ground Dexter stops, phones his partner Hannah—a former killer herself from season seven - and asks to speak to his son Harrison to whom he says: "I just want to tell you one last time that I love you. I want you to remember that every single day until I see you again. Daddy loves you” (Dexter, Episode 812). They hang up and Dexter uncovers Deb's face, briefly holding it in his hands before picking up her body and dropping it into the sea. He sighs as he watches the white sheet slip beneath the waves. Dexter then turns away and says: “I destroy everyone I love, and I can’t let that happen to Hannah, to Harrison. I have to protect them from me” (Episode 812). He then tacks directly into the storm.

The next scene occurs the following day when clean up of Hurricane Laura-a reference to Dexter's murdered mother-has begun. At sea a Coast Guard cutter spots wreckage in the water, which is immediately recognized as Dexter's boat Slice of Life. But there is no sign of life. Following this Dexter's colleague at the Miami Police Department, Detective Battista, is telephoned with the news that Dexter's boat had been found, 
after which we are taken to Argentina where Hannah and Harrison sit at a café as they await Dexter. Hannah sees the story of Dexter's death as she reads the news on her tablet computer. A five-second-long black pause follows and the audience believes the series has ended. However, after this televisual eternity, a long shot of a logging camp lightens the screen once again. The camera tracks down to a truck as a figure exits and walks toward the rear of the trailer. The figure turns and we recognize Dexter. In the following scene he enters a dingy rooming house and goes to his darkened room. He throws down his coat, sighs, drops his key on the table and sits. He turns toward the window with his hands set on the tabletop. The camera, positioned at eye level directly in front of Dexter, slowly tracks in as he turns to face it, closes his eyes and bows his head. Dexter then lifts his head and stares directly at us. The scene and series fade to credits and music.

In these final moments of Dexter we are returned to the crux of the series as the reproductive future is once more negotiated—and finally determined. Everything changes in this moment, look, and decision. Until the final seconds of the series, Dexter seems to choose death over a life of covering, but then, finally, chooses a life sequestered from family and the affective attachments that these brought him. He infers as much when he arrives to pick up Deb at the hospital, telling of how he tried so hard to fit in but that it is too painful to deal with the attending human emotions. Thus, the spectre of Dexter's "dark passenger” is raised as it had been many times in the series. Will Dexter choose a life of covering in which his "real” self must always remain hidden from those he loves or will he finally embrace the dark passenger and unleash his true nature? (Reisch, 2011, pp. xi-xiv). In short, which version of self-reproduction will survive? Since adolescence, when his adoptive father and detective Harry first discovered Dexter's compulsion to kill, Dexter was forced to follow a strict set of rules regarding the manner in which he committed murder. The Code of Harry, as his father constructed it, allowed Dexter to kill within a moral framework by permitting Dexter to kill only those people who had also murdered but had escaped the law. In this way, Dexter's murders were articulated to reproduction from the beginning by always aligning Dexter with the dominant social order represented by American jurisprudence, or at least vigilante justice when the law failed to apprehend and convict murderers. As an adult, Dexter's covering-how he hid his true nature in efforts to remain undetected as a killer-required extension into all facets of life. One example among many, as Mullins argues, is how Dexter became a blood spatter specialist to enable his blood obsession to be expressed within sanctioned parameters in a form of compensatory gesture (Mullins, 2010, p. 82). Another example occurs early in episode one of season one when the audience is introduced to Rita who he dated because she provided cover and demanded nothing of him from the space of her own abused psyche, leading Barber-Callaghan and Barber to suggest that he is a repeat of Rita's partners of the past (Barber-Callaghan \& Barber, 2010, p. 200). A further example also takes place in episode one as Dexter describes how he has no feelings: "I fake them all and I fake them very well” (Dexter, Episode 101), he tells the audience in one of the signature internal dialogues regularly shared through voiceover. Indeed, innumerable examples of covering stand as central tropes of Dexter throughout its eight seasons. In this sense Dexter always walks a razor-sharp line between conformity and monstrosity—each with its own risks and rewards—over which Dexter ruminates obsessively.

Yet, until the very last moments of the series the monster always returns to humanity. Just as the audience repeatedly witnesses his struggle to determine which self will attain sovereignty, Dexter is also painfully aware of his tendency to re-incorporate into social life in efforts to protect himself and others even at the cost of his own potential monstrous freedom, however circumscribed or short-lived it might be. There are many examples, but 
perhaps the most poignant one is from season one when the Ice Truck Killer reveals himself to be Dexter's brother Brian, whom Dexter does not know; however, Brian plants the seeds of memory for Dexter to discover throughout the season. Brian (AKA Rudy) begins to date Dexter's adoptive sister Deb, who falls in love with him, and Brian hatches a plot whereby he and Dexter will kill Deb together. In the season finale Dexter must choose between remaining hidden and protected within the bounds of the law or accepting a monstrous future with no guarantees except that of his blood relation to Brian. The decision is complicated but Dexter chooses his sister, thus asserting a constructed kinship articulated through his adoptive family over that of a blood relation. At the same time Dexter realizes that he must kill Brian to secure his own reproductive future. In each instance these revelations turn on the form reproduction will take. If choosing to "fit in" places Dexter within the rule of law, as it frequently does in the series, then one must also ask what form reproduction would take if Dexter were to choose his dark passenger and follow his blood brother, a choice that is just as frequently raised in Dexter.

Such questions of choice for the subject are problematized by Judith Butler. In Giving an Account of Oneself, she asks the ultimate question for the subject: "What, therefore, am I?” (Butler, 2005, p. 30). If any account of the self must begin in media res, then how is it possible, she asks, to account for the subject through constitutive processes that continually obfuscate the very sovereignty that is sought through the account itself? The subject permanently negotiates this paradox of the primary opacity of identity and self-knowledge. For Dexter, such paradox is made literal by the obsessive movement between a seemingly false self that he must hide to survive and a true self that is forbidden full expression except through the terms of covering that the Code of Harry provides. As the final moments of the series once again lay bare this question, indeed resolve it, the very nature of the question begs further consideration. For the series, reproduction is woven into normative cycles of birth and death as well as those cycles that we might term more social in form, and which question whether the subject is, in fact, born in blood (i.e. nature/nurture). Moreover, in Dexter's case there are also three central rebirths that occur, so to speak, "in blood”: Dexter's own rebirth when as a child he witnesses his mother's murder by chainsaw in a shipping container; his son Harrison's potential rebirth as he too witnesses his mother's murder at the hand of Dexter's nemesis Trinity in season four; and that which occurs in the final moments of the series as Dexter embraces his monstrous self. Each of these points to the question of sovereignty as Dexter traverses the philosophical terrain of blood relations, the human, good and evil, reproduction and redemption. Each also points toward the future of reproduction within the social order, toward the conventions of fitting in and the freedom without guarantee of potentially monstrous futures.

\section{Beginnings}

Are monsters born or are they made? This is the question upon which studies of psychopathy are consistently based. While remaining an important question at one level, even presenting itself as the ultimate question for understanding psychopaths, it operates as an impasse at another. The impasse is located in a simple equation. Psychopathy is exterior to humanity ergo to be human means that one cannot be a psychopath. Conversely, to be a psychopath must always place one outside the boundaries of the human. The psychopath and the human, then, are always situated in opposition, with empathy standing as the mark that separates them-a point replicated in popular culture representations of serial killers. The earliest and still most palatable refutation of this framework is Adolph Guggenbuhl-Craig's The Emptied Soul, which argues in favor of a notion of 
psychopathy as interiority. While this notion has recently been taken up in a more popularized model to analyze the psychopathy of bosses, partners, and neighbors, ${ }^{3}$ Guggenbuhl-Craig argues more fundamentally that everyone possesses psychopathic traits: "each of us is missing something or has some aspect that is markedly underdeveloped” (Guggenbuhl-Craig, 1980, p. 61). Rejecting notions of the psychopath as the constitutive exterior of the human, Guggenbuhl-Craig argues instead that psychopathy involves the underdevelopment of eros in the subject, which can produce personality traits rooted in domination. For him, all humans lack this development in some sphere(s) of life.

The fulcrum around which Dexter's serial killer nature turns is that of blood relations, which refer to both kinship lines and events focused on blood. Dexter's monstrosity, the identification he holds to his dark passenger, occurs at the intersection of these two registers. In this sense Dexter is born twice. Firstly, he is born to his birth mother Laura, who is an informant for Dexter's adoptive father Harry, a police officer. Secondly, when Laura is discovered to be an informant, Dexter, as a young child, witnesses her murder by chainsaw in a shipping container. This event Dexter refers to as his "birth" as a serial killer, one to which he unconsciously returns each time he kills and takes a specimen slide with a blood sample as a trophy. It is also the event that marks the major transformation in blood relations in the series as Dexter is metaphorically born and blood relations shift from the kinship register to that of the social.

Three days after his mother's murder Dexter is rescued by Harry from the shipping container where the murder occurred. Dexter is then adopted by Harry and his wife, who already have a daughter named Deb. Harry learns about Dexter's propensity to kill when Dexter is in early youth and develops the Code of Harry as a response to Dexter's compulsions. Around this time Harry's wife dies and Deb becomes isolated within the family as Harry and Dexter bond through the secret of Dexter's dark passenger. Deb always tries to connect with Dexter but is never able to penetrate the mask he dons to cover his true self, and Deb comes to later realize that her father was similarly unknowable, perhaps as Mauro notes due to a family structure rooted in the narcissism of Harry (Mauro, 2010, pp. 163-165). Indeed Howard argues that Harry is a postmodern Prometheus "violating moral and social laws in the name of an ideal [that] does not lead to retribution or vindication" (Howard, 2010, p. 67). As hero or anti-hero Harry leaves his family to struggle with the loss of its beloved matriarch, the secret of its adopted child's true nature, and the ubiquitous alienation that descends as a result. At the same time, this particular constellation of family relations assists Dexter as he later attempts to build a family of his own. He initially dates Rita as cover. He is then introduced to her children, Astor and Cody, and fakes a relationship with them. However, over time Dexter begins to possess authentic feelings toward them. By the time he and Rita marry, Dexter describes the sensation as something akin to love, which when Harrison is born in season four is confirmed absolutely.

From his own desire to cover emerges a self that Dexter never allows himself to believe existed. As real-world serial killers often do, Dexter attempts to remain invisible. However, as this performance is repeated Dexter is slowly transformed into the very being behind which his invisibility was always constructed. In the series, these performative becomings for Dexter mimic models of middle class life in work, home, leisure and family - the idealized ground of reproductive futurism. Such acts of becoming for Dexter, as he vacuously cites a

\footnotetext{
${ }^{3}$ For exceptions to this tendency see: Martin Kantor, The Psychopathy of Everyday Life (2006); Kevin Dutton, The Wisdom of Psychopaths (2013); Adolph Guggenbuhl-Craig, The Emptied Soul: On the Nature of the Psychopath (1980).
} 
copy for which there is no original, to recall Butler's formulation of the performative, slowly produce the thing that they name- the ideal of middle class masculinity. Yet, Dexter is not always adept in his adoption of masculine traits and there are many moments when his performative transformation is called into question—often humorously—in the series; however, the slow incorporation of Dexter into this model stands as a core value for the series until the very end, even as he plans to escape with Hannah and Harrison to begin a "normal” family life in Argentina. In this sense, Dexter becomes a type of modern "everyman” as he struggles to define "the good life” under conditions not always of his own making. Indeed, if it weren’t for Dexter's dark passenger, the series would have been a simple narrative of incorporation that asserts normative reproductive futures at every level. The series needs Dexter's dark passenger.

As mentioned, there are moments in Dexter that intervene in the reproductive future. In these moments exist alternatives to the regularities located in the class model that the series repeatedly underlines for Dexter. Yet, such alternative reproductive futures are quashed in favor of incorporation, prised open only to once again undergo narrative closure each time. One example of this tendency resides in Harrison. Born from the familial bloodline inherited from Dexter and Rita, and into the structure of middle class family values, his future is guaranteed even as Dexter periodically questions whether Harrison will develop into a serial killer, as he had. Dexter reassures himself through reference to the innate goodness of Rita as a parent. However, when Trinity discovers Dexter's plot to kill him in season four, Trinity avenges by killing Rita in his signature fashion. This he performs by sitting in a bath behind his victims, severing arteries in their legs with a straight razor and holding them in his arms while they bleed to death, rendering the bath water a crimson hue. In Rita's case, Trinity does so in front of Harrison who Dexter returns home to find in a pool of blood on the bathroom floor, crying as Rita lies lifeless in the bath. Just as Dexter was "born in blood" at the scene of his own mother's murder, so too does Harrison's witnessing of an eerily reminiscent scene place the seed of reproductive fear in Dexter's mind. In so doing the scene also generates an important question: If Dexter's dark passenger was born in blood in the moment he witnessed his mother being murdered, then, will Harrison become a serial killer too? The answer in the TV series turns out to be no; however, the spectre of such a monstrous birth is raised, just as other reproductive futures are presented only to then be resolved and fade away, at least until the final moments of the series.

In this context it is important to delineate between the aporetic articulation of Dexter's birth as a serial killer and other forms of birth in the series. For Dexter, the scene of being born in blood is not, in fact, a birth at all. It is also not about bloodlines as expressed through kinship relations. Rather, when Dexter witnesses his mother's murder as a young child it is a metaphorical birth that he experiences. No less powerful for being so, Dexter's dark passenger - the very form of the monstrous for the series—is instantiated at this singular moment as a psychological switch is flipped in his mind. At the same time, never in the series is the suggestion that Dexter may have been coded as a serial killer before this—or at birth—raised. This birth, then, is absolutely social in form. Dexter's particular form of being born in blood actually raises no alarm for genetics or the genealogical relations of blood in the series. This is doubly the case as viewers discover in season one, when the Ice Truck Killer turns out to be Brian, Dexter's blood brother who was not only present to witness their mother's murder but who also became a serial killer.

Such monstrous births repeatedly appear in popular and academic literature to frame serial killers as non-human beings (Schmidt, 2005, p. 30). Just as Dexter privileges the human as an ontological presence with an 
identity that coincides with the totality of the body and mind that figuratively underlines it so too do representations of serial killers in cultural theory and popular culture. As Mark Seltzer argues, referring to Michel Foucault's biopolitics, in the modern era discourse on serial death shifted from acts to types of person to provide the ground upon which to consider serial killers through the lens of psychological character (Selzer, 1998, p. 30). Within this framework, a total picture of a particular character type could be determined, allowing for a series of techniques to emerge for understanding, and ultimately regulating, this unique biopolitical entity. Yet, trauma, especially in childhood, unremittingly forms the center within this mode of analysis. ${ }^{4}$ From here, a question is inevitably asked: What went wrong? Presuming the innocence of the child, a point taken from philosopher John Locke and extending back to Aristotle which frames the mind of the infant as a tabula rasa, the over-determined discourse of childhood trauma promotes and maintains a notion that serial killers become monsters, that they are, indeed, not born in blood. Moreover, even while traumatic events from childhood mark the birth of the serial killer in this model, such becoming within the category of the human still does not forestall the absolute determination of serial killers as being non-human.

In the case of Dexter, the traumatic childhood event of witnessing their mother being murdered is the singular reason provided for Dexter and Brian becoming serial killers. Similarly, a repetition of this trauma at the scene of Rita's murder is upheld as that which has the potential to also transform Harrison into a serial killer. However unlikely, this singularity is posited to be of such force to the child that it has the power to transfigure him from human to monster in an instant. As an adult, a further relay is produced between Dexter's desire to remain undetected and the laws that allow him to kill according to the Code of Harry. Remaining undetectable keeps the monster hidden while also seducing Dexter into the performative circuits that will furnish the affective economy he slowly acquires through such feelings as empathy, love, happiness, etc. At the other end of the spectrum, Harry has produced an alternative system of justice for Dexter alone to live by, encouraging Dexter to direct his need to kill toward those who have also killed. By way of this apparatus Dexter's monstrosity places him on the side of law and order. It also delivers to Harry an extra-legally decreed killing machine for the Miami Police Department, which Dexter comes to realize was one of Harry's objectives from the beginning. Dexter fails to follow the code only a few times in the series, which produces in him the all-too-human feelings of guilt and remorse, but he is also made into a media hero in season three as the Bay Harbor Butcher when the story of his vigilante justice becomes known. Importantly, Dexter experiences this impasse of identity from the beginning to the end of the series as a problem to be overcome. He simply needs to choose which he is: human or monster.

For Judith Butler such volition for the subject is a ruse from its point of origin, as the question "Who, therefore, am I?” must always be asked in media res rather than as a simple question that the subject can answer through the fullness of self-knowledge and sovereignty. She writes:

The norms by which I seek to make myself recognizable are not fully mine. They are not born with me; the temporality of their emergence does not coincide with the temporality of my own life. So, in living my life as a recognizable being, I live a vector of temporalities, one of which has my death as its terminus, but another of which consists in the social and historical temporality of the norms by which my recognisability is established and maintained... Paradoxically, it is this interruption, this disorientation of the perspective of my life, this instance of an indifference in sociality, that nevertheless sustains my living. (Butler, 2005, p. 35)

\footnotetext{
${ }^{4}$ See Schmidt’s account of Ted Bundy on the influence of childhood for serial killer discourse, especially pp. 213-216.
} 
Equally, the norms by which Dexter makes himself recognizable are not fully his own. This is to say that when it comes to knowledge of the subject, self-recognition is but one vector in a matrix through which recognisability is established and maintained. Dexter experiences the problem of self-recognition sharply as he repeatedly alternates between a desire for middle class life with a seemingly secure and predictable reproductive future, and a desire to follow his dark passenger into a reproductive future with no guarantees.

In this quest for self-knowledge exists an analogy for understanding serial killers within community. If elements of the subject are not recognizable to the subject itself, then is it possible that elements of community are also unknowable within its own terms of recognition? This is the case with serial death. To recall Guggenbuhl-Craig's argument from earlier in this article, all subjects exist with psychopathic traits, which is to say that psychopathy does not form a constitutive exterior to the subject but exists within it, if on terms not always the subject's own. Roberto Esposito extends this idea to the register of community. Rather than understanding community simply as an entity that must protect itself from exterior threats through gestures that close and seal its boundaries, Esposito argues that community depends on its negative being injected into its own body in a homeopathic gesture (Esposito, 2011, p. 8). True to convention community is formulated upon that which is common; however, for Esposito it also requires obligation and reciprocal exchange in the form of a "gift" that must be given. Yet, inscribed in the logic of communitas so defined is immunitas. The one who is exonerated from gift giving and communal obligation experiences immunity, which separates the individual from the expropriative effects of the community. In biopolitics, where life itself is the communal value, immunitas takes the form of death inserted into life's very logic. Serial killers embody precisely this relation of immunity to community — death inserted into the logic of life itself—as they are exonerated from communal obligation and the reciprocity of the gift as a bearer of life. Serial death, then, is not an external entity to be eliminated but an internal element to be acknowledged within the very terms of community's logic of presence, a necessary negative of the biopolitical defined today as the "power to foster life" (Esposito, 2011, p. 34).

\section{Rebirths}

This incorporative biopolitical drive, which is threaded through all eight seasons of Dexter, is always subtended by reproductive futurism, as suggested already. Through reproductive futurism Lee Edelman wishes to examine "terms that impose an ideological limit on political discourse as such, preserving in the process the absolute privilege of heteronormativity by rendering unthinkable, by casting outside the political domain, the possibility of a queer resistance to this organizing principle of communal relations” (Edelman, 2004, p. 2). Although Edelman's context for reproductive futurism is queer politics, the concept begs for broader application. Indeed, thinking through reproductive futurism opens a broad spectrum of thought and representation to analysis as it has become a predominant discourse of the contemporary period. ${ }^{5}$ Yet, such potential must not blind one to

\footnotetext{
${ }^{5}$ There are numerous examples of contemporary television series that question reproductive futures. Modern Family uses the concept as the basis for comedy with questionable parenting tactics always presented in tension with the child's future. Homeland positions the main character's mental state, career and national security in opposition to her child's well-being, and Carrie chooses career every time. In The Fall a social worker with a family that he manipulates, uses and endangers as he murders young women is the main character. Perhaps the best example is Breaking Bad in which the main character tries to be a good husband and father by formulating and selling very high quality methamphetamine, a practice and business that complexly traverses the discourse of reproductive futurism at every turn. The reproductive future may even constitute a genre of representation today. At the very least a study of reproductive failure as a theme of contemporary film and television would be useful.
} 
the particular constellation of reproductive relations embedded in any given form. In the case of Dexter as each "birth" takes place questions of moral life are imbricated in serial death within a complex frame of reproductive futurism. As such, the series mobilizes the figural child as the embodiment of the reproductive future, as a limit on political discourse to which there can be no opposition. As Edelman argues: "to serve as the repository of variously sentimentalized cultural identifications, the Child has come to embody for us the telos of the social order and come to be seen as the one for whom that order is held in perpetual trust” (2004, p. 1). The figural child underpins a social order that must be reproduced, with the child's inheritance defined as the core value at every level. In this it is not only the protection of children in the most literal sense that buttresses reproductive futurism so much as the future itself being the ultimate political umbrella under which each child stands. Edelman, for his part, asks what it would look like to not be fighting for the children, in a gesture from "the other side of politics" where he hopes to position queer subjects (2004, p. 7). Much like Esposito's discussion of immunitas as the necessary negative of community, Edelman calls for the queer to figure a negativity —embodied in the death drive and its attending jouissance - opposed to every form of social viability (2004, p. 9). As a form of radical dissolution of the social contract and its governing fictions the queer insists "on enlarging the inhuman instead — or enlarging what, in its excess, in its unintelligibility, exposes the human itself as always misrecognized catachresis, a positing blind to the wilful violence that marks its imposition” (Edelman, 2004, p. 152). To embrace this surplus, this impossibility, this inhumanity, is the ethical task of the queer for Edelman (Edelman, 2004, p. 109). Similarly, such a theoretical embrace, such immunity for the queer, one might argue has already been accomplished by the serial killer.

As has been suggested already the reproductive future is a key feature of the series Dexter, as well as an ongoing concern for Dexter himself. As the entity that must stand as the ultimate foil to evil, reproduction is presented in the series at the pinnacle of its ideal form, as close to irony as possible —at times even crossing the line through the series' particular brand of dark humour. A career in forensics with the Miami Police Department, a quaint pastel pink bungalow in the suburbs, a perfect modern family - these are just a few of the marks that guarantee the reproductive future for Dexter. As he attempts to cover his dark passenger by incorporating his own body and identity into the system of reproduction, these are upheld as ideals in the series. Yet, each also exists at the outer limit of stereotype, at the point where mimicry reaches mockery, at the border where jouissance originates and materializes, so that the audience is always brought to the edge of the system of reproduction as questions about its nature, and Dexter's own, arise. Dexter's impasse-his internal struggle between incorporation and discorporation, between the mythical "good" of covering and the "evil" of his dark passenger - as much as being the crux around which the entire narrative turns, also complicates this framing of reproduction. On one hand, as has been argued here, his attempts to cover and fit in are easily understood as underpinning the reproductive future. On the other hand, Dexter is a killer. When he acts on his dark passenger's urges, on his evil impulses, these should position him as an immune response that inserts death into the community and the very logic of life itself, if Esposito is correct. However, the Code of Harry dis-articulates this dis-corporation and renders Dexter's murders into a further guarantee of the reproductive future. As Dexter kills, social order and rule of law are secured. In this, Dexter's evil is a particularly neo-liberal brand as Byers notes (Byers, 2010, p. 143). Murder is writ large as moral action as the serial killer is inscribed as a (re)productive citizen. In Zizek's account of a certain “fundamental paradox of the 'passion for the Real'” products are deprived 
of their malignant nature: coffee without caffeine, cream without fat, beer without alcohol, sex without the body, multiculturalism without the other, etc. (Zizek, 2002, pp. 10-11). To these Dexter adds: incest without taboo; evil without malice; and, especially, moral death without the law. In this sense, Dexter the serial killer is a very, very good bad boy. Killing through the frame of the Code of Harry, he also secures the reproductive future for himself and the community—not as an immune response but as a valued member of the community (e.g. when Dexter is heralded as a vigilante hero called the Bay Harbor Butcher in season three). For this, Dexter Morgan is a monster we love.

The final scene of the series is important because it provides viewers with a rationale to finally understand Dexter's aporetic self-definition. Fans may have been correct to be angered at the effort to redeem the series in its final moment, but a question must also be asked: How could it have ended otherwise? Redemption is the key to understanding the final plot twist. Throughout the series, each of the main characters seeks to redeem her/his own life in the face of both serious and quotidian challenges. Dexter is no different in this regard. Yet, for him redemption involves making the ultimate decision for the subject. To this end, Dexter posits Butler's question otherwise: What, therefore, am I, good or evil? If he chooses to be good, then he will benefit from the reproductive future and the life it prescribes for him with Hannah and Harrison. Yet, in so doing his true nature is betrayed - not to mention his fans. To redeem himself according to our contemporary wound culture's codes of self-knowledge and identity, with their attending demand to "be true to yourself", in fact, demands that Dexter choose his dark passenger and live as a serial killer outside of the Code of Harry. This is his truth. It is perhaps the final dark joke of the series that Dexter follows his authentic self in its final moments. By doing so, Dexter is redeemed as a subject at the very moment that he takes up the mantle-or perhaps responsibility is a better word - of becoming death within life, of becoming immunity within community, of becoming the necessary negative within reproductive futurism. If the finale provides the redemption that Dexter sought throughout his life-his own self-acceptance as a killer-then it also provides a theoretical opening in reproductive futurism as Dexter's life of immunity points him toward monstrous futures that provide no guarantee for him or for the community in which he lives. Having finally, painfully, woefully found his true and authentic self, what more could we wish for the monster we love than his own happiness?

\section{Conclusion}

The last scenes of Dexter, in which Dexter finally embraces his identity as a serial killer, were crucial to the series. In those moments Dexter finally acts on his fundamental drive to kill and in doing so attains the security of self-identity that he had sought for eight seasons. Separated from family, career and the demands of social life-where covering his truth produced only contradiction, Dexter chooses to live as an outsider on the margins of social life, and life-itself, as a serial killer. By considering this choice through the lens of reproductive futurism, this article has advanced scholarship on Dexter in three ways. Firstly, it argues that Dexter's ultimate choice is crucial for the series as it provides both the required spectacle of the finale and ensures that the series ends by striking the dark note on which it began. Secondly, critically examining reproductive futurism challenges reproduction's positivist place at the centre of representation and politics. As a partner, father, worker and citizen, Dexter tried to be good, and repeatedly failed. His dark passenger always re-emerged, just as his insecurities arose at every turn. This paradox was a fulcrum of the series. Positioned as 
identitary failings to be overcome Dexter worked hard to cover for his dark passenger, to fit in and perform according to the demands of the reproductive future. But in the final instance he chooses his dark passenger, thus underlining the third contribution of this article. By positioning the serial killer and the monster on the inside of community—as the necessary negative of social life—a useful framework emerges for theorizing the role of serial death within biopolitics. Dexter's finale brilliantly, if ironically, figured this theoretical gesture by allowing Dexter to follow his true self into a reproductive future without guarantees for reproduction, community or indeed life itself.

\section{References}

Arellano, L. (2012). The heroic monster: Dexter, masculinity, and violence. Television and New Media, 16(2), 131-147.

Barber-Callaghan, D., \& Barber, N. (2010). Rita’s rocky relationships. In B. DePaulo (Ed.), The psychology of Dexter (pp. 193-205). Dallas, TX: Smart Pop.

Butler, J. (2005). Giving and account of oneself. New York: Fordham University Press.

Byers, M. (2010). Neoliberal Dexter? In D. Howard (Ed.), Dexter: Investigating cutting edge television (pp. 143-156). London and New York: L. B. Tauris.

Dietz, J. (2013). Episode review: Dexter series finale. Metacritic. Retrieved from http://metacritic.com

Edelman, L. (2004). No future: Queer theory and the death drive. Durham and London: Duke University Press.

Esposito, R. (2011). Immunitas: The protection and negation of life. (Z. Hanafi, Trans.). Cambridge, UK and Malden, MA: Polity. Green, S. (2011). Dexter Morgan’s monstrous origins.Critical Studies in Television, 6(1), 22-35.

Guggenbuhl-Craig, A. (1980). The emptied soul: On the nature of the psychopath. Puttnam, CT: Spring Publications.

Howard, D. (2010). Harry Morgan (post)modern Prometheus. In Douglas Howard (Ed.), Dexter: Investigating cutting edge television (pp. 61-77). London and New York: L. B. Tauris.

James, M. Jr. (Creator). (October 2006-June 2013). Dexter (Seasons 1-8). [Television series].

Mauro, M. (2010). It's all about Harry: Is the Morgan family a narcissistic family? In B. DePaulo (Ed.), The psychology of Dexter (pp. 163-179). Dallas, TX: Smart Pop.

Mullins, M. (2010). The scientist and the serial killer. In B. DePaulo (Ed.), The psychology of Dexter (pp. 79-93). Dallas, TX: Smart Pop.

Reisch, G. (2011). Know thyself? In R. Greene, G. Reisch, and R. Robinson-Reisch (Eds.), Dexter and philosophy (pp. xi-xiv). Chicago and Lasalle, Ill.: Open Court.

Schmidt, D. (2005). Natural born celebrities: Serial killers in American culture. Chicago and London: University of Chicago Press. Seltzer, M. (1998). Serial killers: Death and life in America's wound culture. New York and London: Routledge.

Zizek, S. (2002). Welcome to the desert of the real. London and New York: Verso. 